\title{
Determination of Anatomical Location to the Parts of Female Genital System of Awassi Ewes By Us- ing Laparoscopy
}

\author{
K.M.Sali
}

Department of Anatomy, Collage of Veterinary Medicine. University of Mousal, Iraq

With 10 figures $\quad$ Received in September, accepted for publication in October 2010

\section{Abstract}

The purpose of this study was to determine the anatomical location of parts of the female genital system of the Awassi ewes and to describe the relation of these parts with the organs present within the abdominal and pelvic cavities using laparoscopy. Seven Awssi ewes were used for this study.

The Laparoscopic images showed the location of the ovaries, oviduct, uterine horn, broad ligament of the uterus and ovarian artery in vivo and in dorsally recumbent position. Also those images showed the relation of different parts of genital system with other organs of the abdominal and pelvic cavities.

\section{Key words}

Anatomy, Laparoscopy, sheep, Female genital system

\section{Introduction}

Endoscopic surgery is rapidly becoming a popular alternative to tradi- tional operative procedures for a variety of medical and surgical problems. An endoscope is an optical instrument that is designed to help visualize the interior of hollow bodies with a small entrance opening (Fischer, 2002) .Endoscopy is a technique that allows examination of an area of the body by means of an endoscope a tube- like instrument with lenses and a light source attached. The endoscope provides visual examination of the interior of the body through a natural body opening such as throat or through a small incision into the body (saber, 2008). Laparoscopy involves insertion of a fibroptic endoscope through the paralumbar fossa to allow inspection of the abdominal portion of the reproductive tract. This technique allows visual inspection of these structures (Trotter, 1999). Laparoscopy makes photographing the anatomic structures within the peritoneal cavity possible. Laparoscopy as a learning device helps us to recognize and understand the limits of ovary and provides bases for determining the location of female genital system and in assessing the estrual status of heifers and 
cows. Laparoscopy indicates that it is a delicate but simple tool for investigation of the bovine reproductive tract and that it can be used successfully under field condition (Seeger, 1977). The laparoscopy is considered as amazing method for recognizing easily the parts of the genital system (Freeman, 1999). Characterization of the normal laparoscopic images of different animals is, however, essential for veterinary, radiologists, clinicians and surgeons to interpret these images correctly (Epstein, 2006).

Laparoscopic anatomical descripttion of the abdominal cavity and genital system of different animal are available in the works of (Galuppo, 1995 ; Galuppo, 1996 ; Wilson, 1983 ; Wildt, 1977 ; Wildt et al., 1982 ; Bush et al.: 1978, Jainudeen et al., 1982) in addition to one paper in sheep (Snyder, 1974). There is a little information about the laparoscopic anatomy of sheep. This study aimed to provide a laparoscopic images for the female genital system of awassi Iraqian ewes.

\section{Materials and Method}

Seven ewes were used in this study; all ewes were kept under the same environmental and nutritional conditions. The animals age ranges between 7-9 months, and its average body weight ranges between 45- $50 \mathrm{~kg}$. The ewes were prepared for the laparoscopic surgery by the following procedure described by Alwataar( 2006).
1- Fastening the ewes for $12 \mathrm{hrs}$. before the surgery

2- A sedative was administered by Intramuscular injection with xylazine at the dose of $0.05 \mathrm{mg} / \mathrm{kg}$ body weight

3- The site of operation (The abdominal region from the xiphoid cartilage to the pelvic region.) were prepared by: shaving the wool, washing and disinfecting with lodine solution. A local anesthetic was infiltrated at the site of the incision.

4- The position of the animal was dorsally recumbent and the head was put in a down position with 45 degree to the angle of the table. (AlWataar, 2006).

5- During the laparoscopic procedure the abdomen was kept distended or filled with carbon dioxide , the process of distending the abdomen is referred to as insufflations. The distension is important because it increases the visual access to many of the abdominal organs (Epstein, 2006) .

6-The laparoscope is attached to a video camera for viewing on a television monitor.

7-The video movies were converted to the disk and the images of the organs were obtained from the movies by V.C.C. program . 


\section{Results}

Laparoscopic examination of the abdomen in dorsally recumbent ewes with their heads down is the best for observation of the genital system because the abdominal viscera are displaced cranially. The images which obtained in this study revealed the following :

Fig (1) this image shows general view of the abdominal and pelvic cavity .The abdominal muscles appear as: the left and right rectus straight abdominal muscles, the internal oblique abdominal muscles. The pelvic inlet and the urinary bladder which appear clearly in all images.

The urinary bladder appears dorsal to the uterus because the animal is in a dorsal recumbent position, the ascending colon also appears in the right side at the pelvic inlet (Fig. 2)

The intercornual ligament was not identified in direct images of the uterine horn. It could be seen when the horn is pulled away, in Fig (3) the intercornual ligament appeared clearly because the uterine horn was pulled away.

The uterine horn and oviduct were observed, the urinary bladder and the descending colon were also identified on the left side. (Fig 4).

The uterine horn, the oviduct and ovarian artery which extends through the broad ligament was detected in Fig (5).
The right ovary and right oviduct as well as, the broad ligament is observed together with the right ovarian artery (Fig 6).

The left ovary, left oviduct and left ovarian artery were observed in Fig (7).

The proper ligament of the left ovary can be observed when the uterine horn is elevated, the left broad ligament together with left ovary were also identified here in (Fig.8).

The ascending colon (proximal loop) at the right and the jejunum at the left were exposed here and the urinary bladder was also clearly observed in (Fig. 9).

The uterine horn, urinary bladder, left broad ligament and right oviduct were observed in Fig (10).

\section{Discussion:}

A complete and thorough understanding of the laparoscopic anatomy of a dorsally recumbent animal can enhance the diagnostic and therapeutic capabilities of sheep laparoscopy. Laparoscopic images provide normal clear view of the organs in proper position and direct images for student, surgeons, and veterinarians for using to recognize the viscera in normal size and position.

In the present study the laparoscope insertion site that allows optimum observation of the genital organs was on 3-4 cm. caudal to the 
umbilicus at the midline of the body ,this result was not in agreement with (Fischer, 2002) who reported that the site of insertion for horse in dorsal recumbent position was mid way between the xiphoid cartilage and the umbilicus $15-20 \mathrm{~cm}$. cranial to the umbilicus. Ewold et al. (2006) mentioned that the site of insertion was through the left flank in sheep to reach the uterine horn and the ovary. In this study the broad ligament appears clearly with the vessels of the ovary and uterus, this result was in agreement with (Freeman, 1999) who mentioned that the laparoscopic study provides best view for understanding the location of uterus and ovaries in bitches and mentioned also that the broad ligament of bitch extends from the caudal border of the kidney and contains the arteries and veins of the uterus.

The ovary, oviduct and ovarian artery could be easily observed, while the proper ligament of the ovary could be observed only when the uterine horn was elevated. This result was in agreement with (Seeger, 1977) who mentioned that the uterus and ovaries could often be viewed without other instruments, best results were achieved when a blunt forceps was used to manipulate the ovaries, oviduct, uterus and adnexa . Also Trotter (1999) mentioned that the laparoscopy involves insertion of a fibroptic endoscope through the paralumbar fossa to allow inspection of the abdominal portion of the reproductive tract. This technique allows inspection of ovaries, the fimbria, oviduct and uterus. Moreover, Snyder (1974) stated that laparoscopy was effective for evaluating reproductive status, particularly ovarian anatomy and function, this technique has been used mainly as a research tool for studying the female reproductive organs and their activity in sheep. While Fischer et al. (1986) mentioned that the laparoscopy in horse in caudal portion of the abdomen allows visualization of large intestine, inguinal ring, ovaries and horn of the uterus. Bush (1978) found via the laparoscopic observation of the female genital tract of bear that each ovary was encapsulated in an ovarian bursa and could not be visualized directly. This type of reproductive anatomy appears to be prevalent in domestic and wild canids. Jainudeen et al. (1982) stated that the laparoscopy was a simple reliable and rapid technique for repeated observation of the ovaries in the buffalo.

\section{Acknowledgments}

The author would like to thank Dr. Muneer Al- Badrani the director of Endosurgery unit in the college of veterinary medicine, Mousal university and Mrs. Braa D. Al-wataar for her help in providing the laparoscopic movies. 


\section{References}

\begin{abstract}
AL-Wataar B.D. (2006): Comparison of Laparoscopic intrauterine insemination and with intracervical inseminatin in synchronized Awassi ewes, a Thesis .presented to the University of Mousal, Iraq.
\end{abstract}

Bush ,M, Wildt ,D.E, Kennedy ,S ,Seager ,S.W. (1978): Laparoscopy in Zoological medicine J.Am. Vet.Med. assos. 1081-1087.

Epstein ,K.P Parent ,E. (2006):

Equine Laparoscopy www.acvs.org. The American college of veterinary surgeons.

Ewold,J.M., Anderson ,D.E, Hardy,J.S., (2006): Evaluation of sheep laparoscopic uterine trauma modle and repeat laparoscopy for evaluation of adhesion formation and prevention with sod. Carboxtmethlcellulose. www.cababstractsplus.org

Fischer,J.R, Kentlloy,K.C , Carlson G.B , Madigan ,J.E (1986): Diagnostic Laparoscopy in the horse. JAVMA . vol. 189 no. $3: 289-292$.

Fischer, A.T ,(2002): Equine Diagnostic surgical Laparoscopy, W.B. Saunders Company, Philadelphia , London , Newyourk .

Freeman L.J ,Dean ,A.H ,(1999):

Veterinary Endosurgery, Mosby inc. Westline lindustrial Drive .st. Louis, Missouri Gluppo L.D, Snyder ,J,R ,Puscoe
J.R. (1995): Laparoscopic Anatomy of the Equine abdomen, Am.J. Vet. Rese. 56: 518-531.

Gluppo L.D. Snyder , J.R. , Puscoe ,J.R(1996): , Ventral Abdominal Approach for Laparoscopic Anatomy of the abdomen in dorsally recumbent horse. Am. J. Vet, Rese. 57: 923-931.

Jainudeen, M.R. ,Bongso , T.A.

Bashir ,A.F. (1982): Alaparoscopic technique for in vivo observation of ovaries in the water buffalo (Bubalus bubalus). Veterinary Record 111 :32-35

Saber A.S (2008): Implementing Imaging Facilities and Multimedia in Teaching Veterinary Anatomy, J.Vet. Anat. Vol. 1 no 1: 48-53.

Seeger ,K. (1977): Laparoscopic Investigation of the Bovine Ovary, VM/ SAC june: 10371044.

Snyder D.A. Dukelow ,W.R.

(1974): Laparoscopic studies of the Ovulation, pregnancy diagnosis and Follicle aspiration in sheep, Therniogenology, 2 : 143-148.

Trotter G.W. Enbertson R.M.(1999): Equine surgery. W.B. Saunders Company Philadelphia 2nd ed. Chap. $59: 575$.

Wildt ,D.E Kinny, G.M, Seeger W.J. (1977): Laparoscopy for direct observation of internal organs of domestic cat and dog , Am.j.vet. rese 38 (9) 1429-1432.

Wildt, D.E Chakraborty ,D.K. , 
Gambre,R.C.(1982): Laparoscopic Evaluation of Reproductive organs and abdominal cavity content of the Lowland Gorilla . Am. J. primatol 2: 29-42.
Wilson, G.L. Kinny ,G.M. , Seager, W.J. (1983): Laparoscopic Examination of Mares VM/SAC 78(10): 1627-1633

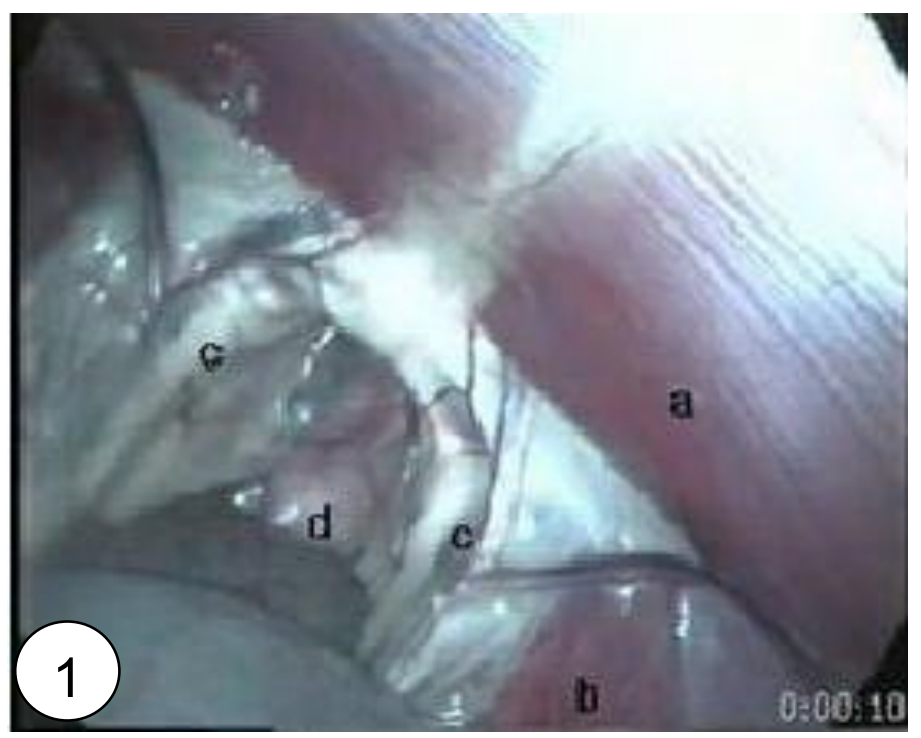

Fig (1): Laparoscopic image of the sheep abdomen showing a Rectus abdominis muscle, b internal oblique abdominal muscle, c pelvic inlet, d urinary bladder.

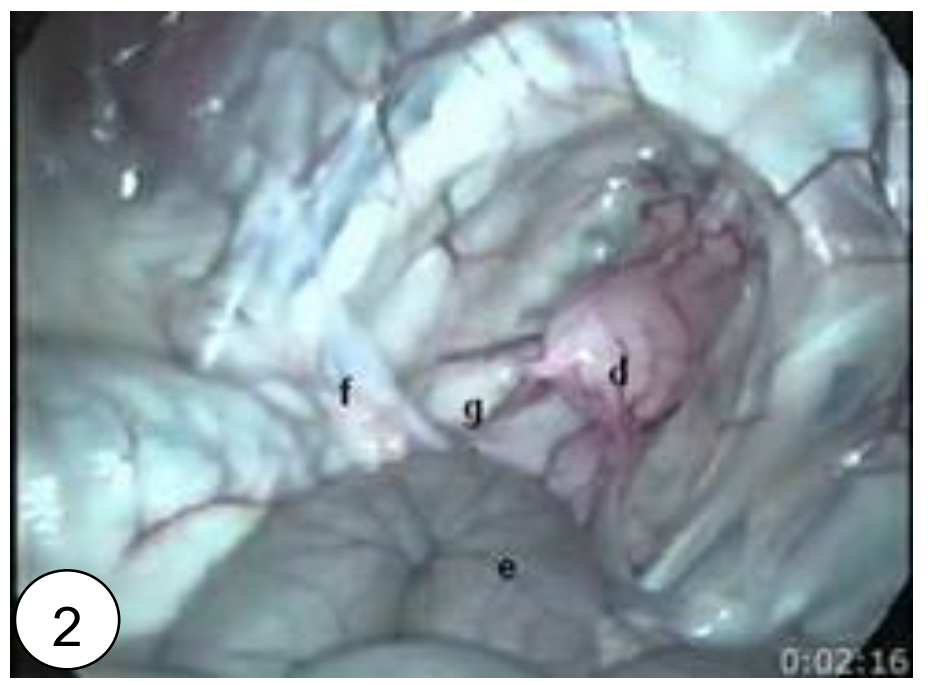

Fig (2): Laparoscopic image of the sheep abdomen showing: d urinary bladder, e ascending colon, $g$ uterine horn, $f$ broad ligament. 


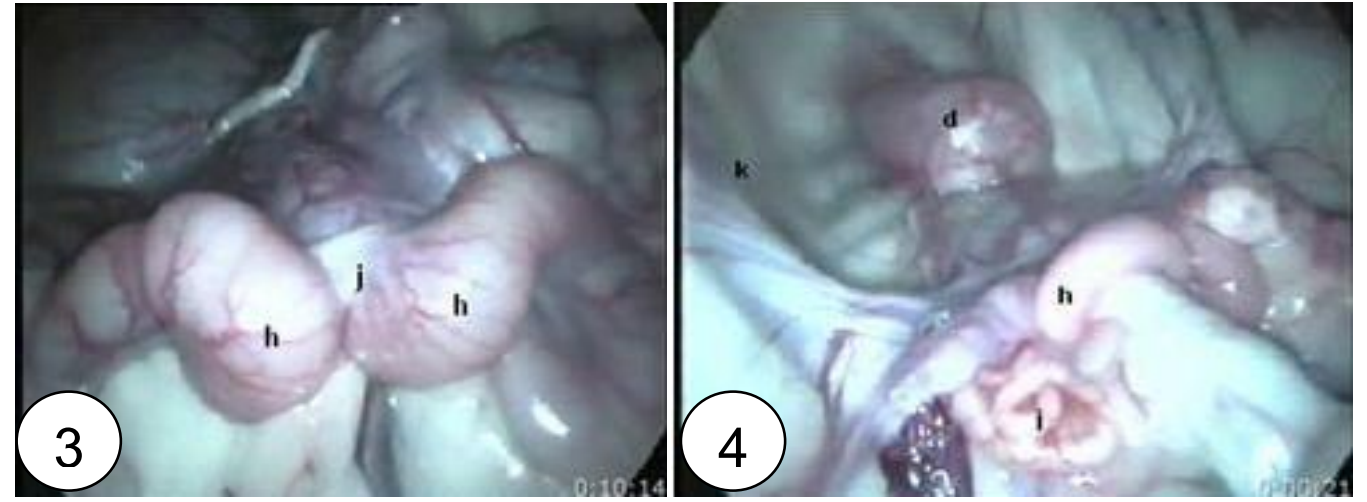

Fig (3): Laparoscopic image of the sheep pelvis showing: $h$ uterine horn, $j$ intercornual ligament.

Fig (4): Laparoscopic image of the sheep pelvis showing: $h$ uterine horn, $\mathrm{i}$ oviduct, $\mathrm{k}$ descends colon, d urinary bladder.

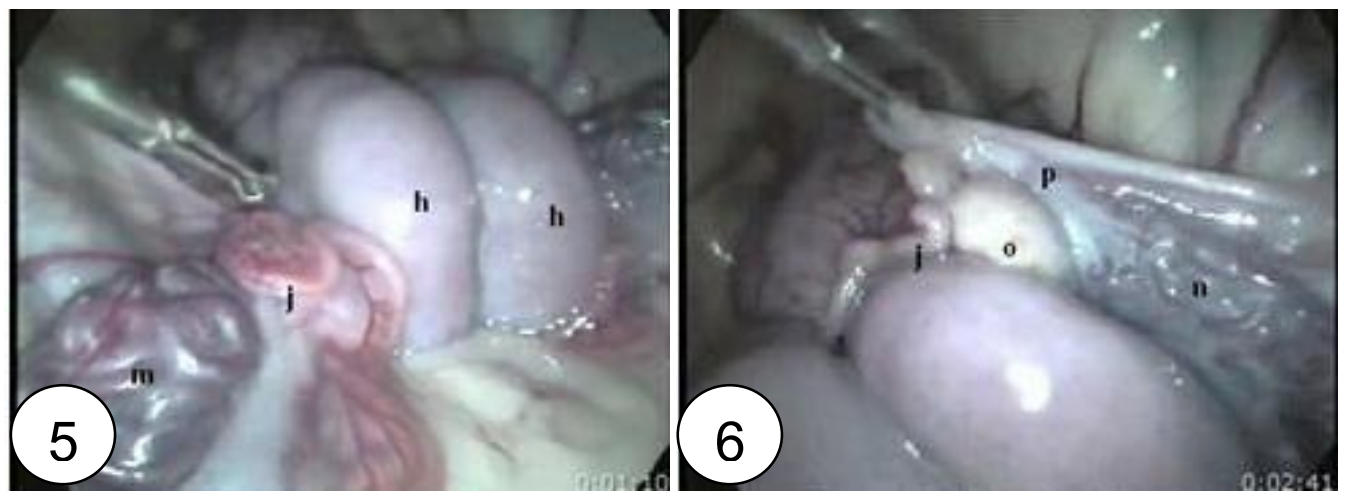

Fig (5): Laparoscopic image of the sheep pelvis showing: $h$ uterine horn, $\mathrm{j}$ oviduct, $\mathrm{m}$ ovarian artery.

Fig (6): Laparoscopic image of the sheep pelvis showing: o right ovary, j right oviduct, $p$ broad ligament, $\mathrm{n}$ right ovarian artery. 


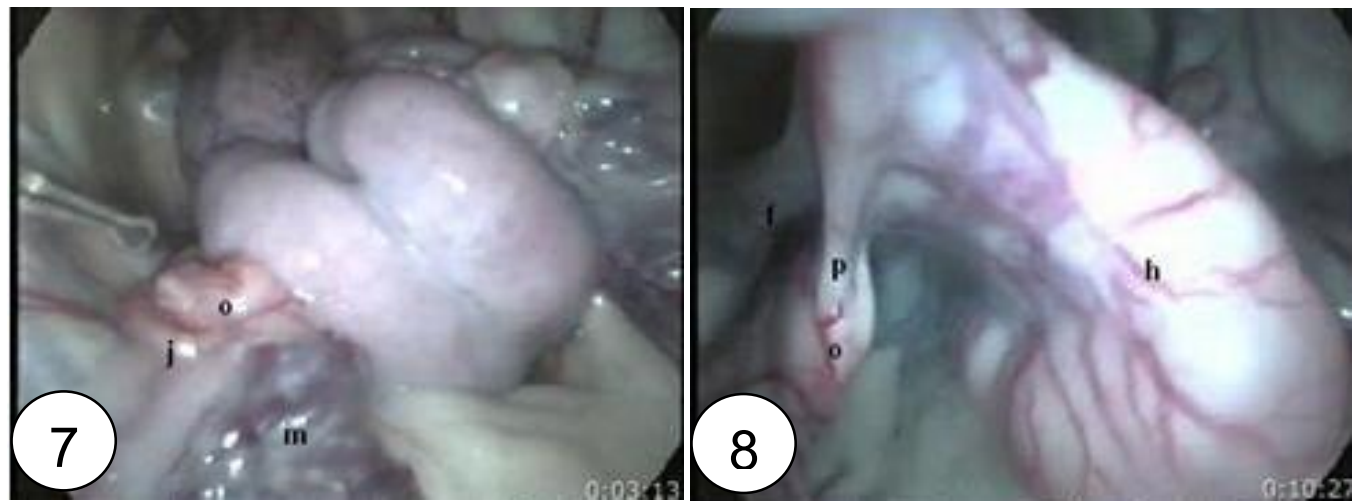

Fig (7): Laparoscopic image of the sheep pelvis showing: o left ovary, j left oviduct, $\mathrm{m}$ left ovarian artery.

Fig (8): Laparoscopic image of the sheep pelvis showing: $h$ left uterine horn, $p$ left proper ovarian ligament, o left ovary, f left broad ligament.

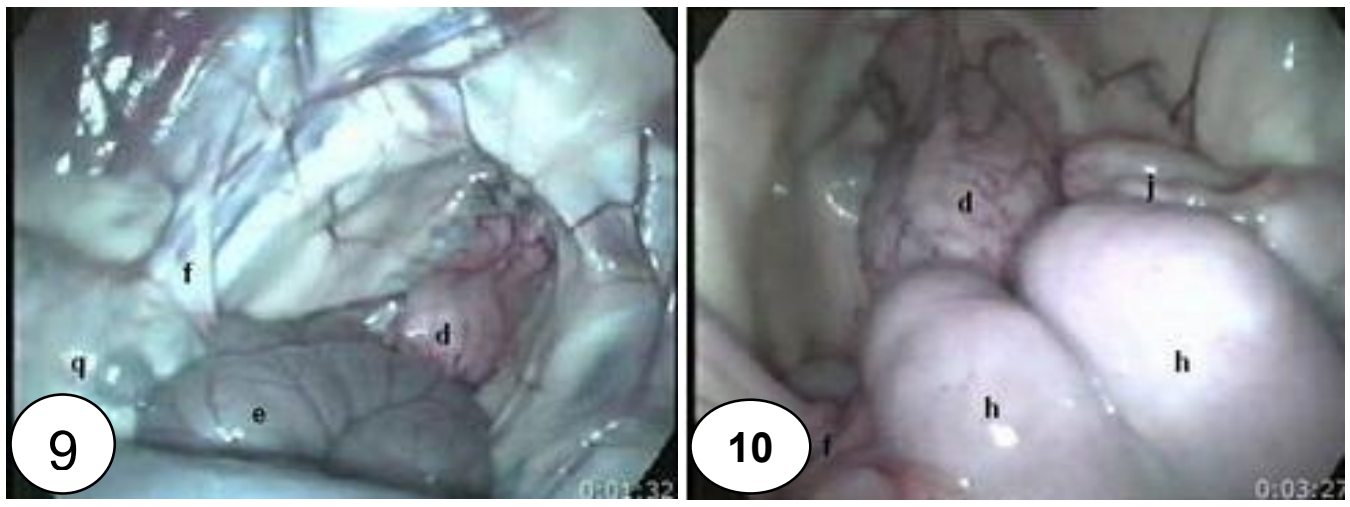

Fig (9): Laparoscopic image of the sheep abdomen showing: d urinary bladder, e ascending colon, f broad ligament, q jejunum.

Fig (10): Laparoscopic image of the sheep pelvis showing: $h$ uterine horn, $d$ urinary bladder, f left broad ligament, j right oviduct. 